\title{
The Effect of Music Teacher Education on Musical Taste of Music Majors
}

\author{
Doruk Engur ${ }^{1}$ \\ ${ }^{1}$ Music Education Department, Bursa Uludag University, Bursa, Turkey \\ Correspondence: Doruk Engur, Music Education Department, Bursa Uludag University, Bursa, Turkey.
}

Received: September 11, 2019

Accepted: October 15, 2019

Online Published: December 30, 2019

doi:10.5539/ies.v13n1p98

URL: https://doi.org/10.5539/ies.v13n1p98

\begin{abstract}
In this study, it was aimed to determine the level of change of music education students' musical taste after they have received four years of music education given within the scope of the Music Education Undergraduate Program. To achieve this purpose, a cross-sectional survey was employed. Therefore, 12 pieces were selected to represent each category of Baroque, Classical, Romantic, and 20th-century music, and the first, second, third, and fourth-year students were asked to score the pieces out of 7 according to their musical taste. The results show a linear trend decreasing from Baroque to 20th-century music. However, the year of education of the students does not have a significant effect on their musical taste.
\end{abstract}

Keywords: aesthetics of music, music preferences, musical taste, music teacher education

\section{Introduction}

Various definitions of music, which is thought to have begun with the history of humanity, have been made. Within the framework of an approach that combines the basic points in many of these definitions, Ucan (2005) says that music is an aesthetic whole that processes and expresses emotions, thoughts, designs and impressions with sounds combined with a specific purpose and method and with a precise understanding of beauty. In order to have a better understanding of this definition, which considers music as an aesthetic whole based on sounds; it will be useful to emphasize the word aesthetics. The origin of the word aesthetics, a branch of philosophy, is based on the Greek word aisthanomai, which means perception through the senses, and the aistanomai is based on the word perception and sensation. In this respect, it is possible to define the word aesthetics as an epistemological word used in the sense of the information revealed by our senses and perceptions (Tasdelen, 2012).

Baumgarten used the word aesthetics in the sense of the perception of beauty through the senses and made aesthetics a field that explores sensory competence, which is beauty. Thus, sensory knowledge turned towards the beauty phenomenon and aesthetics was accepted as a subfield of philosophy researching beauty (Tasdelen, 2012). In this case, it is not wrong to conclude that when the issue of aesthetics is a topic of consideration, one needs to think on what beauty is.

It is challenging to make a definition of beauty accepted by everyone because the understanding of beauty varies from person to person, and even in the same person, different beauty judgments may appear in different situations. For example, when events or objects that cannot be considered as beautiful are the subjects of art, one may like it. In his work; Poetics, Aristotle said, "When an object we look at in dislikes, in reality, becomes a particularly complete painting, this time we look at it in pleasure; for example, as in the pictures of the animals and corpses that revolted" (Aristotle, trans. 1987).

However, Kant differentiated between beautiful and pleasant. According to Kant, the feeling of pleasant emerges from some certain interests or benefits, whereas beauty is not based on benefits. To elaborate Kant's idea via a musical example; it is possible for us to find a piece of music pleasant because it reminds us of our childhood, but we need to evaluate its motive development, formal characteristics, and harmonic structure in order to say that it is beautiful. However, it is not possible to clearly determine the characteristics that a work of art should carry in order to qualify it as beautiful. Nevertheless, there are contemporary philosophers such as Guy Sircello (1936-1992), who believes that the principles of beauty can be identified. In this respect, although we give subjective reactions in determining beauty, it can be said that there is an objective aspect of beauty (Tasdelen, 2012).

Yildirim and Koc (2011) say that music philosophy is the act of thinking on the creation process in the ontological 
dimension of music. Thus, thought and taste emerges and creates the aesthetics of music. Music aesthetics contribute to beauty judgment and facilitate the formation of our tastes. In the formation of our likes, our level of knowledge about the work and the characteristics of the period of the work are of great importance.

Furthermore, there are other aspects which determine our preferences. Berlyne (1960) thinks that psychophysical variables which mean perceivable differences such as loudness, ecological variables about associated meaning or memories, and collative variables including complexity, familiarity, or ambiguity are the determiners of a person's preferences.

Berlyne (1969) stated that there are two contending systems to determine the preferences; namely rewarding and aversion systems. They, basically, follow one another which means after initial arousal level has been reached, aversion system activates. The influence of this opposition results in the inverted-U curve in the distribution of data obtained through preference studies. According to the inverted-U theory preferences are expected to increase as the collative variables (for example, complexity) increase up till to a peak level, and from that point, preferences begin to decrease.

However, there are some studies showing only a positive correlation or only negative correlation. Chmiel and Schubert (2017) stated that those results show presumably only the first or the second part of the inverted-U and therefore those studies do not disprove the theory. In their research Chmiel and Schubert (2017) investigate the studies on collative variables done over 115 years and conclude that the results of $87.7 \%$ of the analyzed studies are parallel with the inverted-U model.

Another opinion to choose what we like or not belongs to Yildirim and Koc (2011), who pointed out the cultural accumulation carried by the works by saying, "Every musical work calls us with aesthetic judgments that have philosophical foundations from the corridors of history." However, it is also important to know what extent the cultural accumulation carried by the work will affect the audience. The interpretation of these "voices from the corridors of history" is also related to the experience and culture of the listener. In this respect, it can be said that music's composition, interpretation, and perception processes are directly related to culture. In this respect, Cook (2000), who wants to draw attention to the strength of the relationship of music with culture, states that music is embedded in culture. Furthermore, Tuzun (2013) emphasized the effect of culture by saying "Music and language are structures that are not innate and are organized by communication systems acquired depending on the culture."

Communication between people is essential in the formation and transfer of culture. People use the languages we have developed based on icons to provide this communication. Another way for humans to express themselves is art, which is unquestionably a higher-level method. When we consider art as a method of self-expression based on abstract representations, it is possible to say that music has a different place in terms of using the sound of its material. Altar (1996) states that in the art of music, the incarnation of the power of thinking and imagination into composition makes this art naturally different from the other arts; because the main element that tries to give a visible body to the art of music is only the sound, and the only expressive power that this physical element creates in the way of shaping the narrative is the symbolic language specific to music.

Even in works whose art value is accepted worldwide, it is possible that each individual will find different meanings and different tastes. Although it is tried to be understood what the artist wants to tell, the works of art are tried to be understood through the special meanings acquired in the mind of the associated aesthetic expression. Therefore, the way the individual interprets the work of art and the depth of these interpretations are related to the breadth of the individual's accumulation in the field of culture (Ergur, 2013).

In line with the above opinions, it can be said that the education received within the framework of the Undergraduate Program in Music Teacher Education will contribute significantly to the music culture accumulation of the prospective teachers. In this study, the level of the effect of the education received in the context of the program on the music taste was worth investigating.

When the literature is reviewed, there are some studies related to the current study. Chronologically ordered, one of the earliest studies carried out in 1972. In Canada, a study of the music preferences of 7th-grade students tried to determine the extent to which a pre-set listening program will affect music preferences. In this study with two experimental and one control groups, the first experimental group was given information about compositions and composers for analytical listening in music lessons for 14 weeks and samples of important representatives of tonal, polytonal, atonal, and electronic music were played. The second experimental group was informed only about the names of the composers and compositions and the students in this group were allowed to listen to the compositions three times. No listening program was applied to the control group. As a result, it was found that while there was no change in the control group, the appreciation of music genres played in the experimental groups, especially in the first experimental group, was increased (Bradley, 1972). 
J. Peery and I. Peery (1986) conducted an experimental study with preschool children in the USA. Within the scope of the research, after determining the likes of pop and classical music of children, 45 minutes of activities per week were applied to the experimental group for ten months. At the end of these activities, which included listening to classical music, singing classical music themes, and various musical games, it was seen that classical music appreciation was superior to the appreciation of pop music in the experimental group.

Burke and Gridley (1990) selected four recordings of piano music, which the complexity levels were determined by professors at Mercyhurst College. A group of college students consisting of 20 with fewer than two years of musical training and 20 with extensive musical backgrounds was given a task to rate their preferences for those pieces. The results showed an inverted-U curve indicating a low or high level of complexity caused a decrease in preferences.

A descriptive study of the music tastes and preferences of individuals from different social statuses was conducted in Turkey. According to the surveys, it has been concluded that the higher the education level, the more attention is paid to artistic value, and the individuals develop musical tastes close to the general music tendency (Sager \& Imik, 2008).

Another research in Turkey was carried out to determine the effect of art education supported by activities in the preschool period on aesthetic taste levels of children. In the experimental group, Visual Arts Education was given once a week and in the control group, the course was taught by the traditional method. As a result of the study, it was determined that there was a significant difference in aesthetic judgments of the experimental group receiving Visual Art Education (Davun, 2009).

In a study by Williams (2016), undergraduate music majors and nonmajors were asked to rate their enjoyment for the musical excerpts they listened to during the application. The results showed that music majors preferred the classical genre, while nonmajors preferred popular music.

Senol-Sakin (2016) conducted a study concerning the opinions of music majors on $20^{\text {th }}$ and $21^{\text {st }}$ centuries' music. One of the results of this study showed that students mostly studied the works of Baroque, Classical, Romantic, and $20^{\text {th }}-21^{\text {st }}$ century periods respectively. Senol Sakin's study also showed that students did not recognize modern composers sufficiently and they rarely listened to modern compositions.

\section{Method}

\subsection{Study Group}

Subjects were determined through convenience sampling among the volunteer students who are enrolled in a Music Education Program at a state university in the 2018-2019 educational year. Thirteen first-year students, 7 sophomores, 8 juniors, and 11 seniors participated in the study. Twenty-two of the students were female and 17 of them were males. They had been playing at least an instrument for $8.08 \pm 3.48$ years.

\subsection{Data Collection Tool and Procedure}

Totally 12 excerpts for baroque, classical, romantic and 20th-century periods (three for each period) were selected. Using Google forms, 7-Likert-type liking questions ( $1=$ dislike, $7=$ like) for each excerpt were prepared. Since the google forms platform does not support sound files, excerpts were included as links to $\mathrm{mp} 3$ files from google drive. Participants were asked to click on the link and listen to the first excerpt and turn back to the form to grade it on their own musical taste, then they went on grading until 12 excerpts were finished. In order to prevent the participants from being biased, they were not given any information about the composer or the composition in the form. The links of the forms were sent to the students via the department's Facebook group which consists of only students enrolled in the department. Table 1 represents the orchestral works which participants were asked to grade. 
Table 1. Orchestral works used in the study

\begin{tabular}{lll}
\hline Period & Composer & Composition \\
\hline \multirow{3}{*}{ Baroque } & Johann Sebastian Bach & Brandenburg Concerto No. 2 in F major, BWV 1047 I. Allegro Moderato \\
& Antonio Vivaldi & Concerto Grosso in G Minor RV578 III. Larghetto \\
& George Frideric Handel & "Water Music" Suite No.1 in F Major, HMV 348: IX. Andante \\
\hline \multirow{3}{*}{ Classical } & Joseph Haydn & Symphony No. 45 in F-sharp minor Adagio \\
& Wolfgang Amadeus Mozart & Symphony No. 41 in C major, "Jupiter" - III. Menuetto: Allegretto - Trio \\
& Ludwig Van Beethoven & Symphony No. 6, Op.68 - II Andante molto moto \\
\hline \multirow{3}{*}{ Romantic } & Johannes Brahms & Hungarian Dance No. 15 - Allegretto Grazioso \\
& Camille Saint-Saens & Danse Macabre \\
& Modest Musorgski & Pictures at an Exhibition: Promenade \\
& Arnold Schoenberg & Orchestration: Sergei Petrovitch Gortchakov \\
\hline \multirow{2}{*}{20 th-Century } & Alban Berg & Three Pieces for Orchestra, op.6 I. Praludium: Langsam \\
& Anton Webern & Symphony, Op.21 - I. Ruhig schreitend \\
\hline
\end{tabular}

\subsection{Data Analysis}

To determine the internal consistency correlations of participants' rates for the same period excerpts were calculated. Three correlation coefficients were calculated for each period (for example, correlations between 1st and 2nd, 1st and 3rd, 2nd and 3rd excerpts of Baroque period). Subsequently, the arithmetic mean of these correlation coefficients was calculated and Spearman-Brown formula was carried out to determine the internal consistency for the related period. The internal consistency coefficients for Baroque, Classical, Romantic, and 20th-century periods were $.67, .48, .46$, and .55 respectively.

Participants' total scores for each period were analyzed. In order to determine any possible effect of the year factor (whether the students are in their 1st, 2nd, 3rd, 4th year in university) on the musical taste, Kruskal Wallis-H test was employed for each Baroque, Classical, Romantic, and 20th-century periods.

Changes in periods rates were also analyzed using a repeated ANOVA with one within factor (4 levels: Baroque, Classical, Romantic, and 20th-century).

\section{Results}

Participants rated all 12 excerpts between 1 and 7. Among these excerpts, there are 3 samples from 4 different periods. For each period, participants' scores for all three excerpts were added up so that the participant's score for each period could range from 3 to 21 .

Table 2. Kruskal Wallis-H Test results which show the effect of year of education on musical taste

\begin{tabular}{lcccccc}
\hline Period & Year of Education & $N$ & $M$ & $S D$ & $H$ & $p$ \\
\hline \multirow{4}{*}{ Baroque } & 1st Year & 13 & 15.00 & 3.851 & 0.325 & 0.955 \\
& 2nd Year & 7 & 14.71 & 2.498 & & \\
& 3rd Year & 8 & 15.75 & 3.284 & & \\
& 4th Year & 11 & 15.09 & 3.961 & & \\
\hline \multirow{5}{*}{ Classical } & 1st Year & 13 & 14.00 & 3.215 & 2.670 & 0.445 \\
& 2nd Year & 7 & 14.86 & 3.532 & & \\
& 3rd Year & 8 & 16.38 & 3.335 & & \\
Romantic & 4th Year & 11 & 15.09 & 3.300 & & \\
& 1st Year & 13 & 13.31 & 3.276 & 4.417 & \multirow{2}{*}{0.249} \\
& 2nd Year & 7 & 15.86 & 2.340 & & \\
& 3rd Year & 8 & 15.75 & 3.327 & & \\
20th-century & 4th Year & 11 & 14.55 & 4.034 & & \\
& 1st Year & 13 & 12.85 & 2.512 & 3.909 & 0.371 \\
& 2nd Year & 7 & 13.57 & 4.276 & & \\
& 3rd Year & 8 & 15.88 & 3.523 & & \\
\hline & 4th Year & 11 & 13.18 & 3.842 & & \\
\hline
\end{tabular}


As seen in Table 2, students' scores did not differ according to their year of education in university ( $\mathrm{p}>.05$ ). Scores were substantially close. There was no evidence to suggest that an increase in educational level affects scores.

Table 3. Repeated measures ANOVA results of musical periods

\begin{tabular}{lcccccccc}
\hline Period & $N$ & $M$ & $S D$ & $S S$ & $d f$ & $M S$ & $F$ & $p$ \\
\hline Baroque & 39 & 15.13 & 3.450 & 47.76 & 3 & 15.921 & 3.210 & 0.026 \\
Classical & 39 & 14.95 & 3.300 & & & & & \\
Romantic & 39 & 14.62 & 3.423 & & & & & \\
20th-century & 39 & 13.69 & 3.518 & & & & & \\
Residual & & & & 565.49 & 114 & 4.960 & & \\
\hline
\end{tabular}

ANOVA results in Table 3 showed that students' scores were significantly different for Musical Periods, $F(3,114)$ $=3.210, \mathrm{p}=0.026$. In further analysis, polynomial contrasts were used to investigate whether the data had an inverted U-shape or a linear slope.

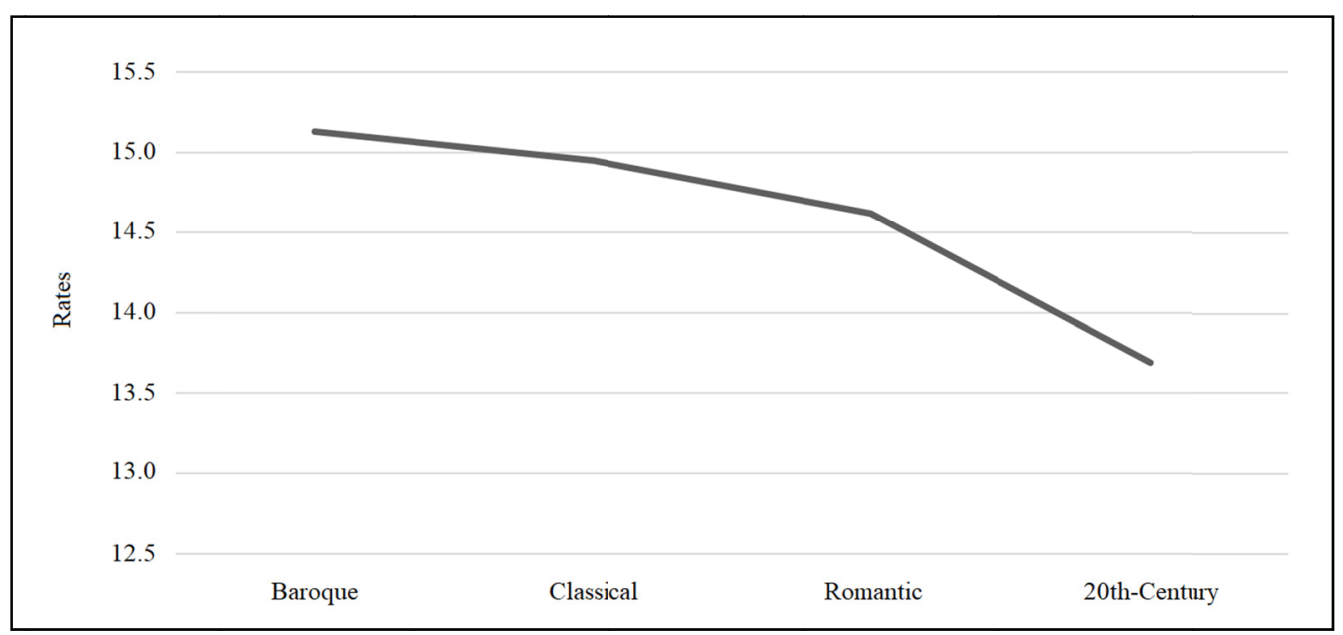

Figure 1. Students' rates for the musical periods

Contrasts revealed a significant linear trend, $F(1,38)=8.915, p=0.007$ as indicated in Figure 1. As seen in the figure as the music changed from Baroque to 20th-century, students' rates decreased. Students enjoyed the Baroque music the most, and the least enjoyed was the 20th-century.

\section{Discussion and Conclusion}

In this study, all the participants were students at the Music Department, and they were asked to state their liking of the music excerpts from Baroque, Classical, Romantic and 20th-century periods. The results indicated that students' scores did not differ according to their year of education. This may seem different from other studies that provide evidence that education affects music enjoyment. However, it is necessary to take into consideration that in studies whose participants are music majors and nonmajors (Williams, 2016), or which an experimental study conducted training the experimental group (Bradley, 1972; Davun, 2009; J. Peery \& I. Peery, 1986), the effect of education would be more precise. Nevertheless, it can be concluded that the impact of the few years spent in the Music Education program is not large enough to be determined by this current study since there is a limited number of participants.

When students' tastes related to musical periods are examined regardless of the year of education, results showed a linear trend in which the students like the Baroque period the most and the 20th-century the least. It can be thought that the reason for this result is the collative variables that Berlyne (1960) mentioned. Considering that the selected excerpts' complexity increases from Baroque to 20th-century, we could expect results that support Berlyne's (1960, 1969) inverted-U. Furthermore, since the students mostly studied the works of Baroque, Classical, Romantic, and 20th-21st century periods, respectively (Senol-Sakin, 2016), one can expect them to perceive modern music as more complex. Based on the opinion of Chmiel and Schubert (2017), studies showing only 
positive or negative correlation do not refute the inverted-U theory, it can be said that the data obtained from the present study represents the second half of the inverted-U shape.

Finally, it can be said that similar studies can be done in order to make a more accurate generalization to musical periods. Such studies with larger participants will reveal the impact of music education on students' musical taste.

\section{References}

Altar, C. M. (1996). Sanat felsefesi uzerine [On the philosophy of art]. Istanbul: Yapi Kredi Yayinlari.

Aristotle. (1987). Poetika [Poetics] (I. Tunali, Trans.). Istanbul: Remzi Kitabevi.

Berlyne, D. E. (1960). Conflict, arousal and curiosity. NY: McGraw-Hill. https://doi.org/10.1037/11164-000

Berlyne, D. E. (1969). Arousal, reward and learning. Annals of the New York Academy of Sciences, 159(3), 1059-1070. https://doi.org/10.1111/j.1749-6632.1969.tb12997.x

Bradley, I. (1972). Effect on student musical preference of a listening program in contemporary art music. Journal of Research in Music Education, 20(3), 344-353. https://doi.org/10.2307/3343887

Burke, M. J., \& Gridley, M. C. (1990). Musical preferences as a function of stimulus complexity and listeners' sophistication. Perceptual and Motor Skills, 71(2), 687-690. https://doi.org/10.2466/PMS.71.6.687-690

Chmiel, A., \& Schubert, E. (2017). Back to the inverted-U for music preference: A review of the literature. Psychology of Music, 45(6), 886-909. https://doi.org/10.1177/0305735617697507

Cook, N. (2000). Music: A very short introduction. New York: Oxford University Press. https://doi.org/10.1093/actrade/9780192853820.001.0001

Davun, B. Y. (2009). Okul oncesi donemde etkinliklerle desteklenmis sanat egitiminin estetik begeni duzeyine etkisi (Sosyal Hizmetler Çocuk Esirgeme Kurumu ornegi) [The effect of art education which is supported by the activities over the aesthetic judgment of pre-school chi (Unpublished $\mathrm{PhD}$ thesis). Gazi University, Institute of Educational Sciences.

Ergur, A. (2013). Kultur [Culture]. In E. Gokalp (Ed.), Sosyal bilimlerde temel kavramlar [Basic concepts in social sciences] (pp. 2-22). Eskisehir: Anadolu University.

Peery, J. C., \& Peery, I. W. (1986). Effects of exposure to classical music on the musical preferences of preschool children. Journal of Research in Music Education, 34(1), 24. https://doi.org/10.2307/3344795

Sager, T., \& Imik, U. (2008). Muziksel begenide sosyal statunun rolu [The role of social status in musical preference]. Erciyes University Journal of the Institute of Social Sciences, 1(24), 273-292.

Senol-Sakin, A. (2016). The opinions of music education students about 20th and 21st centuries classical music: Uludag University Exemplification. Journal of Education and Practice, 7(35), 117-123.

Tasdelen, D. (2012). Estetik ve sanat felsefesinde temel konular [Basic issues in aesthetics and philosophy of art]. In A. Inam (Ed.), Estetik ve sanat felsefesi [Aesthetics and philosophy] (pp. 2-30). Eskisehir: Anadolu University.

Ucan, A. (2005). Muzik egitimi: Temel kavramlar-ilkeler-yaklasimlar ve Turkiye'deki durum [Music education: Basic Concepts-principles-approach and the situation in Turkey] (3rd ed.). Ankara: Evrensel Muzikevi.

Williams, M. L. (2016). The influence of genre and musical training on continuous versus summative ratings of listener enjoyment and response times (Unpublished Ph.D. thesis). Florida State University, College of Music.

Yildirim, V., \& Koc, T. (2011). Muzik felsefesine giris [Introduction to philosophy of music] (5th ed.). Istanbul: Baglam Yayinlari.

\section{Copyrights}

Copyright for this article is retained by the author(s), with first publication rights granted to the journal.

This is an open-access article distributed under the terms and conditions of the Creative Commons Attribution license (http://creativecommons.org/licenses/by/4.0/). 